\title{
NIH faces double trouble over budget rise
}

Matthew Davis, Washington

US biomedical science is experiencing unprecedented growth, with the National Institutes of Health (NIH) on course to have doubled its budget over five years by 2003 . But there is rising concern that if, as is likely, budget increases then start to slow, too much of the agency's money will be locked into multi-year projects, squeezing funding for new grants.

Foremost among those expressing such worries is Senator Tom Harkin (Democrat, Iowa). Last week's power shift in the Senate, after a Republican senator's departure from his party handed control to the Democrats (see story opposite), is expected to see Harkin become chair of the Senate committee that oversees the NIH's budget. In committee hearings last week, Harkin said he was "really concerned" about the NIH's level of commitment to multi-year grants, if budgets tighten in 2004. "There will not be a lot of money left over for new grants," he warned.

The plan to double the NIH's annual budget to $\$ 27$ billion was drawn up partly to address complaints from biomedical researchers about the low success rate of grant applications. The number of NIHfunded research grants has since grown from 27,000 to 32,400 , and their average value has risen by $36 \%$.

Continuing this growth trend would please scientists. But with grants typically running for four years, it would leave the $\mathrm{NIH}$ with little spare cash for new projects if its budget growth slows.

Robert Rich of Emory University in Atlanta, president-elect of the Federation of American Societies for Experimental Biology, says multi-year obligations must be carefully managed if researchers applying for grants after 2004 are not to be shortchanged. But even with smart planning, he claims, problems will only be avoided if the NIH's budget continues to increase at

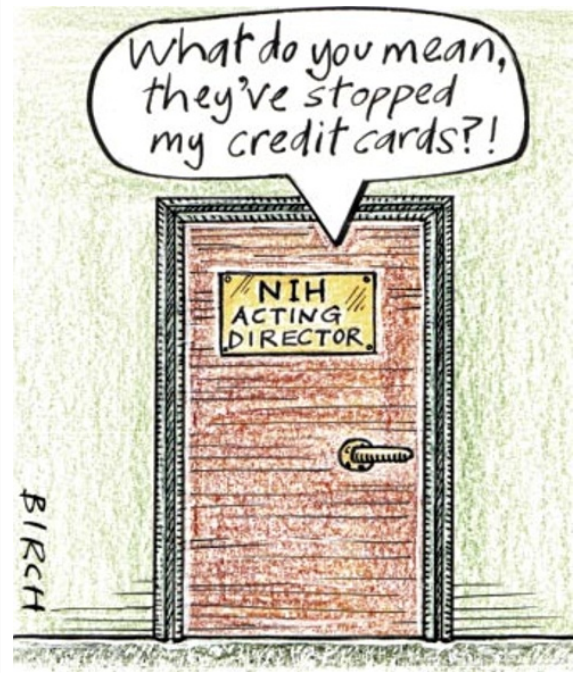

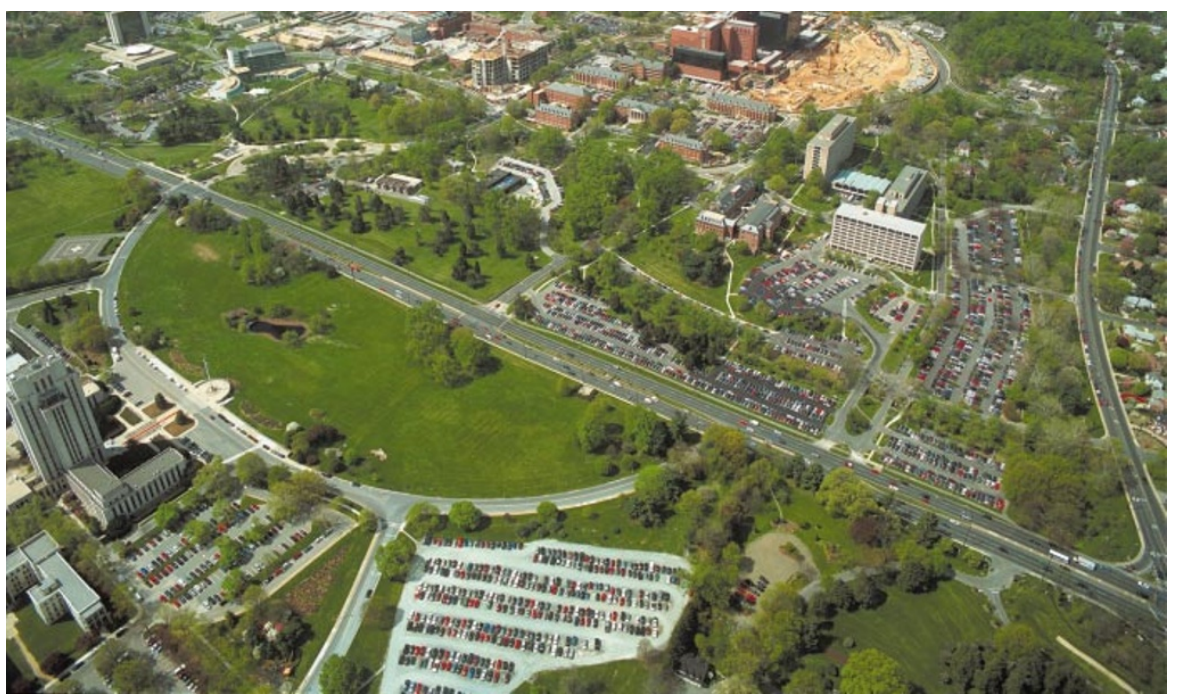

Headache at headquarters: is the NIH locking too much of its money into multi-year research grants?

around $7 \%$ per year. And that may not be realistic, given the US administration's moves to cut taxes, and concerns about a general economic slowdown.

Last week, NIH acting director Ruth Kirschstein told Harkin that the agency plans to set up a committee of institute directors to consider future spending for various projected budget scenarios. But congressional aides say privately that such planning may come too late. And they are concerned that NIH officials are still assuming they will get a succession of multi-billion-dollar increases after 2003.

Francis Collins, who heads the National Human Genome Research Institute in Bethesda, Maryland, agrees that there could be a problem. His institute's budget is heavily committed to projects spanning several years, and the effect on new grants, should NIH budget growth stall, "would be gruesome", he claims. Collins says one approach would be to invest more in facilities, equipment and an array of short-term projects this year and next. But that would mean fewer research grants.

This would be unpopular with researchers who want to benefit from the NIH's current growth. Making the tough decisions that may be necessary to plan for the future would be easier if the agency had a permanent director. But so far the US administration has made no moves to propose a candidate.

\section{Dust settles on defamation case}

\section{Rex Dalton, San Diego}

A long-running battle over claims that a scientific paper defamed the inventor of a radiocarbon-dating technique has finally been settled.

Under the agreement, the state of Arizona, which funds the universities employing both parties to the dispute, will pay Ronald Dorn of Arizona State University in Tempe $\$ 50,000$ to cover legal costs.

Dorn developed his technique to date scrapings of the natural 'varnish' that forms on desert rocks. But a paper in Science (280, 2132-2139; 1998), by authors including Warren Beck, Douglas Donahue, Tim Jull and George Burr of the University of Arizona, Ekkehart Malotki of Northern Arizona University, and Wallace Broecker of Columbia University in New York, reported "ambiguities" in samples obtained from Dorn's lab. The paper concluded that the samples were contaminated with fragments of charcoal and coal — which would have affected the dating measurements.

Dorn became the subject of a misconduct investigation, but was cleared by his university of manipulating his samples in September 1999. In the meantime, he sued the paper's authors for defamation. Broecker settled with Dorn last year (see Nature 408, 506; 2000), but Dorn's dispute with the Arizona authors was, until last week's settlement, heading for an October jury trial.

The settlement means that neither side will risk running up massive legal bills. "Dorn and the authors agree that science is developed through discussion and debate in the literature," says a statement issued by the University of Arizona. Dorn declined to comment. 